\title{
Software Educativo Encantando Cordel
}

\author{
Amanda Maria D. de Oliveira, Adriana Virgínia M. de Azevedo, Gelly Viana \\ Mota, Roberia S. da P. Lourenço, Felipe Gilberto R. Dantas, Dennys L. Maia
}

Instituto Metrópole Digital - Universidade Federal do Rio Grande do Norte (UFRN)

Lagoa Nova - 59.064-741 - Natal - RN - Brasil

\{amanda.marry, roberiamatematica\}@hotmail.com, \{adrianavmazevedo, gellyvianamota1988, felipegdantas\}@gmail.com, dennyseimd.ufrn.br

\begin{abstract}
Motivated by the deficient situation in the school text production work, with a view to literacy and reading and writing, we developed the educational software Encantando Cordel for elementary school students. Educational software is characterized by the use and production of cordéis (creation, reading, and cordel history) in three activities that explore the elements of this genre. Encantando Cordel was developed as free software by a multi and interdisciplinary team and in a collaborative way between students and professor of Pedagogy and Information Technology. This experience shows that it is possible to develop quality software using free or open resources, even if there are still certain limitations and difficulties.
\end{abstract}

Resumo. Motivados pela situação deficitária no trabalho escolar de produção textual, com vistas à alfabetização e letramento, desenvolvemos o software educativo Encantando Cordel para alunos dos Ensino Fundamental. O software educativo se caracteriza pelo uso e produção de cordéis (criação, leitura, e história do cordel) em três atividades que exploram os elementos desse gênero. O Encantando Cordel foi desenvolvido como um software livre por uma equipe multi e interdisciplinar e de forma colaborativa entre alunos e professor de Pedagogia e Tecnologia da Informação. Esta experiência mostra que é possível desenvolver softwares de qualidade utilizando recursos livres ou abertos, mesmo que ainda existam certas limitações e dificuldades.

\section{Introdução}

A dificuldade na leitura e escrita dos alunos é evidenciada nos resultados das avaliações de larga escala, como a Avaliação Nacional de Alfabetização (ANA), atualmente denominado Sistema de Avaliação do Ensino Básico (Saeb), e o Exame Nacional do Ensino Médio (ENEM). Segundo a plataforma QEdu1 que utiliza os dados do ANA ou Saeb, demonstra que $35 \%$ dos alunos do $5^{\circ}$ ano do fundamental no Rio Grande do Norte (RN) aprenderam adequadamente as competências leitura e interpretação de textos, ou seja, estão aptos a continuar os estudos. No entanto, o RN está atrás de Estados do Nordeste como Ceará (63\%) e Pernambuco (42\%). Outro fator sinalizado pelos dados é que o RN ocuparia o $5^{\circ}$ lugar, em um ranking dos piores estados do Brasil nessas competências. Logo, novas práticas pedagógicas são necessárias e urgentes, conforme a meta que consta no Programa Educação para Todos, o que espera que $70 \%$ dos alunos do

1 Dados disponíveis em: <https://www.qedu.org.br/>. Acesso em: 17 de Março de 2019. 
$5^{\circ}$ ano alcancem o aprendizados adequado até 2022.

Diante disso [Almeida 2008], o aprendizado dos alunos pode ser facilitado por meio da utilização dos recursos multimidiáticos para o ensino do letramento, porque os alunos estão inseridos numa sociedade cada vez mais tecnológica, trazendo consigo toda essa carga de novidades para aula, logo, faz-se necessário o acompanhamento de tal evolução pelo professor. Aliado a isso, os resultados do PISA2 [Brasil 2016] apresentou que os alunos possuem maior facilidade para lidar com textos argumentativos, no formato de blogs e e-mails. Fato esse que reforça a importância da utilização das Tecnologias Digitais da Informação e Comunicação (TDIC) na formação do aprendiz.

Segundo a Base Comum Curricular (BNCC) é papel da escola estimular e desenvolver práticas de linguagem e produções textuais, visto que os padrões hodiernos de linguagem envolvem, também, gêneros e textos cada vez mais multimidiáticos, bem como novas formas e recursos para produção, disponibilização e interação, com fins de atender às necessidades sociais para um uso qualificado e ético dos ambientes da Web [Brasil 2017]. A evolução do conhecimento, científico ou social, se dá a partir da disseminação e do compartilhamento, permitindo o desenvolvimento de uma sociedade intelectual livre, democrática e justa [Da Silveira 2004]. Portanto, no atual contexto sóciotecnológico, as TDIC assumem papel relevante para viabilizar essa realidade buscada.

Com isso, no presente artigo, apresentamos o Software Educativo Livre (SEL) Encantado Cordel que visa, por meio do uso da metáfora do cordel, auxiliar na disseminação da cultura regional associando-a ao desenvolvimento do letramento por meio do ensino da leitura e da escrita de cordéis a durante o Ensino Fundamental. Idealizado e desenvolvido por uma equipe multidisciplinar das Universidades Estadual do Ceará (UECE) e Federal do Rio Grande do Norte (UFRN), o Encantado Cordel está sob a licença Creative Commons (CC-BY), que dá o direito do usuário modificar, adaptar e compartilhar o código fonte do software, mesmo com finalidades comerciais, entretanto é necessário fazer referência ao projeto original. Este SEL se classifica como um Objeto de Aprendizagem (OA), tratando-se, portanto, de um recurso educativo digital utilizado no ensino de conteúdo específico com forte característica de reusabilidade [Oliveira et al 2017].

O OA aqui apresentado procura se aproximar da abordagem construcionista [Papert 2008], pois proporciona ao aluno o desenvolvimento de suas estruturas cognitivas a partir da exploração de obras já existentes de cordelistas, e produção de seus próprios cordéis, que possuem em sua essência histórica o poder de despertar no escrevente o senso crítico, por meio das rimas que retratam os problemas do cotidiano. A produção de cordéis, potencializa ainda o desenvolvimento do raciocínio e do pensamento lógico dada a necessidade de cumprir as devidas regras de formação de uma sextilha (caracterizada por ser um texto escrito em versos, no qual as rimas acontecem apenas nos versos pares), por exemplo. Dessa forma o próprio aluno se vê como participativo e construtor de sua aprendizagem, tornando-se responsável e co-autor do processo de ensino e de aprendizagem. É preciso, ainda, apontar que o Encantado Cordel apresenta uma proposta inter e multidisciplinar, na medida em que explora competências de diferentes áreas do conhecimento - Língua Portuguesa, Literatura e Artes - integrando-as no desenvolvimento das atividades apresentadas.

Por fim, este artigo está estruturado com: Introdução, onde o leitor é apresentado ao tema tratado e a relevância do OA proposto; Metodologia, onde é descrita a composição da equipe e suas ações na participação no desenvolvimento do recurso; 
Apresentação do software, que apresenta a atual versão do Encantado Cordel, indicando e justificando as relações pedagógicas e técnicas para o desenvolvimento do OA; fechando com as Considerações finais onde é apresentado o que foi aprendido com a experiência de desenvolvimento deste OA e algumas demandas de trabalhos futuros.

\section{Metodologia}

O Encantando Cordel teve sua concepção iniciada pelos alunos do curso de Pedagogia da universidade UECE e, no ano de 2015, os alunos do curso de Bacharelado em Tecnologia da Informação (BTI) da UFRN iniciaram sua produção gráfica, que foi utilizada como base para o desenvolvimento da versão do OA aqui apresentada. No semestre de 2018.2, no contexto da disciplina de Software Livre, Educação e Cultura, do BTI, foi retomado o desenvolvimento do Encantando Cordel. A turma teve por volta de 7 semanas para realizar este trabalho, que veio a compor parte da avaliação da disciplina. A turma foi então dividida em três grupos, sendo cada grupo responsável pelas demandas Pedagógicas, de Design e Técnicas, respectivamente.

Imbuídos de atender à filosofia de Cultura Aberta [Maia, Pinheiro \& Arrais 2015], foi decidido que todos os grupos deveriam utilizar apenas recursos livres ou abertos. Essa mesma metodologia para o desenvolvimento de SEL foi adotada também no caso dos SEL ContaKg e Brincalculo [Oliveira et al, 2018; Oliveira et al, 2016] que, apesar de ambos tratarem de conteúdos distintos do proposto no Encantando Cordel, serviram como principal referência metodológica para este trabalho, dado que abordam o desenvolvimento colaborativo de OA de acordo com os parâmetros da Cultura Livre. No caso do Encantando Cordel, optou-se que em cada equipe fossem escolhidos dois integrantes (gerentes da equipe) para gerenciar e mediar a comunicação entre os grupos, devido o elevado número de participantes na turma. Os gerentes das equipes optaram por criar um grupo de discussão em um aplicativo de mensagens instantâneas para tirar dúvidas, solicitar e informar demandas, visto que todos faziam uso constante desse aplicativo essa demonstrou ser a opção mais adequada para a situação.

À equipe pedagógica foram atribuídas as atividades acerca da fundamentação pedagógica, como: definição de público-alvo, conteúdos e habilidades a serem abordados; elaboração das mensagens de interação com usuário dentro da abordagem pedagógica construcionista; e a escrita do manual do usuário destinado aos professores que desejam utilizar o software. A ferramenta Draw.ioz foi utilizada pela equipe pedagógica para a elaboração do fluxo de navegação do Encantando Cordel. As atividades da equipe pedagógica foram gerenciadas e organizadas por meio de compartilhamento de arquivos na nuvem via Google Drive4 e as demandas foram geridas com suporte da ferramenta Trello5, um software gerenciador de tarefas que auxilia na organização de etapas, demandas pendentes e prazos.

Com as diretivas deixadas pelas equipes que iniciaram o projeto e da equipe pedagógica, aà equipe de Design ficou incubida do aperfeiçoamento gráfico do SEL; da produção e escolha das imagens (utilizando editores e repositório de imagens livres ou abertas); e o desenvolvimento do storyboard presente no manual do usuário. Devido a grande dificuldade na busca de imagens livres, ou com permissão de uso aberta, relacionadas com cordel ou xilogravuras, foi necessária a criação de imagens que atendessem às demandas. Dentro do que havia sido estabelecido, o grupo procurou utilizar

\footnotetext{
3 Editor gráfico online no qual é possível desenvolver desenhos, gráficos, diagramas e outros.

4 Serviço do Google de armazenamento na nuvem ou backup de arquivos.

5 Ferramenta de gerenciamento de projeto idealizado por Fog Creek Software em 2011.
} 
os softwares de edição/criação de imagens Gimp6 e Inkscape7, porém esses softwares se mostraram de difícil utilização para a criação de gráficos vetoriais, por isso foi aberta uma exceção e foi utilizado o software de edição Photoshop8.

À equipe técnica, foram delegadas as atividades de implementação, teste e implantação do Encantando Cordel. Quando a equipe iniciou o trabalho existiam apenas as definições pedagógica e de design, portanto, a parte de codificação foi realizada desde o ponto zero. O software foi desenvolvido utilizando as linguagens CSS, JavaScript e HTML5, visto que se trata de um software Web e essas são as tecnologias comumente utilizadas para o desenvolvimento deste tipo de software. Para auxílio na implementação das funcionalidades do Encantando Cordel, foi utiliza a biblioteca React de códigos JavaScript, dado que era a biblioteca de conhecimento mútuo entre os membros da referida equipe. O React é uma biblioteca considerada eficiente e flexível para criação de interfaces de usuário dinâmicas.

Dado o caráter colaborativo adotado no processo de desenvolvimento do OA, foi criado um projeto no sistema de controle de versões distribuído GitHub9, para armazenamento e controle das versões do código-fonte, auxiliando nas situações de conflito que surgem no processo colaborativo de desenvolvimento de software. O OA está hospedado para acesso público no HerokuApp 10.

Para a escolha do tipo de licença do Encantado Cordel, a equipe técnica criou e disponibilizou para toda a turma um formulário online do Google Drive que, de acordo com a maioria dos votos, resultou na escolha da licença Creative Commons - Atribuição CC BY, licença mais flexível da Creative Commons, pois permite o livre acesso, distribuição, adaptação e compartilhamento das alterações feitas a partir do que já foi desenvolvido. É permitindo ainda que este OA e suas novas versões sejam utilizadas para fins comerciais, desde que, em qualquer caso, sejam atribuídos os devidos crédito pela criação original.

\section{Apresentação do software}

$\mathrm{O}$ referido OA visa auxiliar no desenvolvimento do interesse pela leitura e desenvolvimento de textos, com a valorização da cultura nordestina, pelo contato com um gênero textual bastante popular na região - a Literatura de Cordel. Por meio de suas atividades (funcionalidades), o Encantando Cordel oportuniza ao usuário criar cordéis, conhecer um pouco sobre sua história e acessar alguns exemplos.

A tela inicial do software é animada, caracterizando elementos inerentes ao cordel e à cultura nordestina. Nesta tela existe a opção de iniciar a navegação ou ver os créditos do OA (figura 1).

\footnotetext{
6 Gimp disponível para dowload em <https://www.gimp.org/>

7 Inkscape disponível para download em: <https://inkscape.org/pt-br/>

8 Disponível para download em: <https://www.adobe.com/br/products/photoshop.html/>

9 Repositório acessível em: 〈https://github.com/encantando-cordel/encantando-web>

10 Plataforma em nuvem utilizada para armazenar softwares Web.
} 


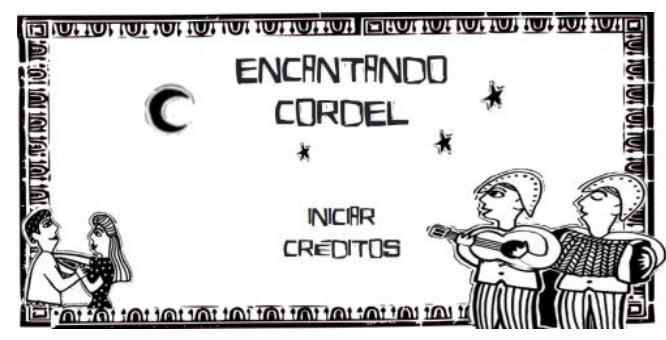

Figura 1. Tela Inicial

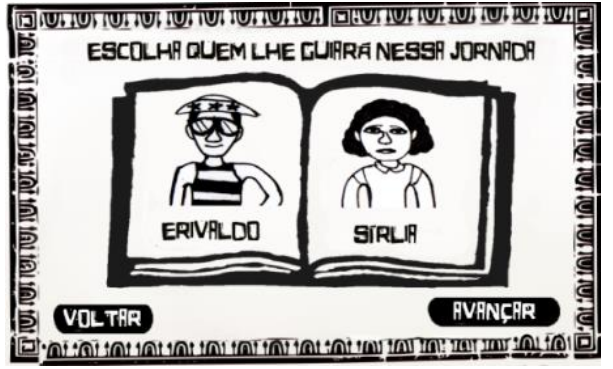

Figura 2. Escolha do personagem guia

Para iniciar a navegação pelo Encantado Cordel é necessário escolher o personagem que vai guiar o aluno durante a utilização do OA, que pode ser o Erivaldo ou a Sirlia, dois cordelistas potiguares da atualidade (figura 2).

Após a escolha do personagem, é apresentada a tela de escolha da atividade que será realizada. Destaca-se que não há um roteiro ou sequência pré-definida que o usuário precise seguir, podendo o professor ou aluno traçar o próprio caminho dentro do escopo de atividades do OA. Tal característica é uma das que aproxima o Encantando Cordel da abordagem Construcionista. Nessa tela, tem-se as três opções de atividades: $i$ ) conhecer a história do Cordel; ii) acessar exemplos de cordel; e iii) criar um cordel (figura 3).

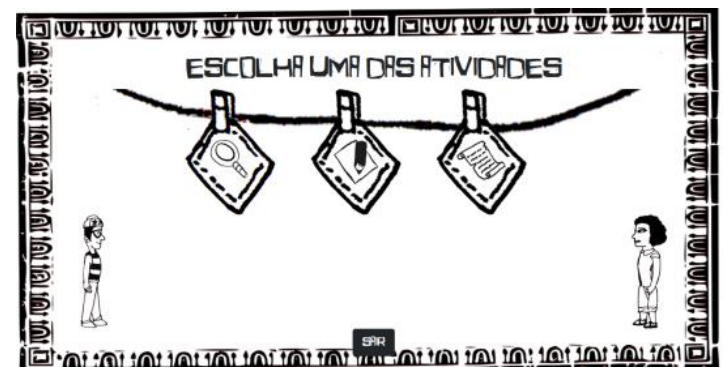

Figura 3. Escolha da atividade

$\mathrm{Na}$ atividade História do Cordel é apresentada a história do gênero cordel, desde onde surgiram os primeiros relatos de cordéis e suas relações com a cultura nordestina. Essa atividade permite que professores e alunos trabalhem o primeiro contato com esse elemento literário da cultura nordestina, conhecendo a origem deste tipo de literatura.

Já na opção de exemplo de cordel, são apresentados três cordéis e o usuário pode navegar pelos botões de avançar e voltar para conhecer os três exemplos. Na última exemplificação é mostrado um cordel que explica e demonstra uma sextilha, que foi a estrutura de cordel escolhido para o desenvolvimento do OA. Esta atividade proporciona ao aluno um contato com um texto de cordel e pode servir de referência, por exemplo, na realização da atividade de criar um cordel, apresentada a seguir.

$\mathrm{Na}$ atividade Ciar Cordel o personagem escolhido orienta como deve ser criada uma sextilha, a principal atividade do Encantando Cordel, a qual apresenta uma abordagem totalmente construcionista visto que, como propõe Papert [Valente 1997], nesse momento o aluno, com o auxílio do computador, atua autonomamente na construção do próprio conhecimento acerca do que é abordado pelo software e com a devida mediação. Por isso, é de grande importância que na equipe de desenvolvimento de um software educativo atuem, também, profissionais especializados em educação.

Para criação do cordel o usuário tem uma tela na qual é possível escolher a xilogravura, simulando a técnica de gravação na madeira para reproduzir uma imagem como um carimbo, utilizado nos desenhos de cordéis. O usuário pode montar livremente as ilustrações do seu cordel, utilizando as opções de "carimbos" e as opções de cor para 
capa, além de colocar um título e digitar o texto de seu cordel (figura 4).

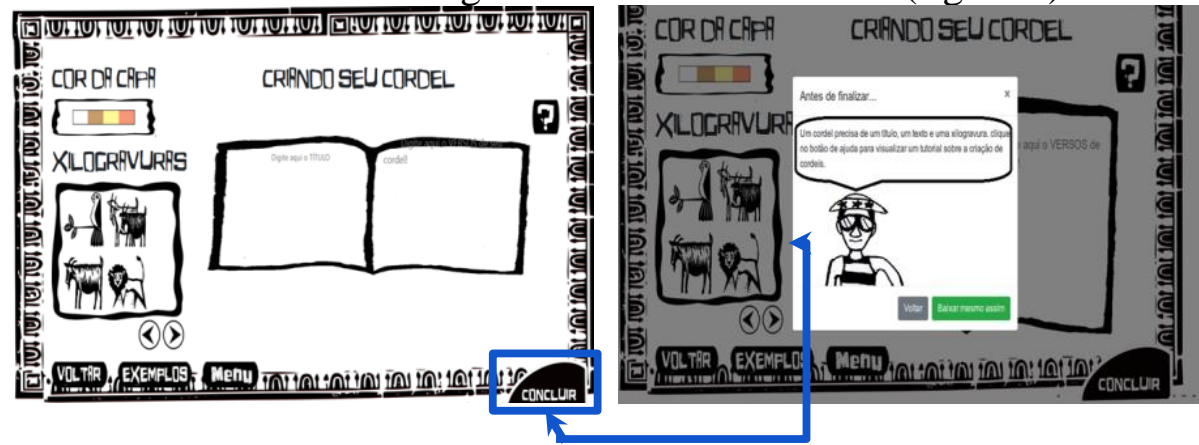

Figura 4. Tela de criação e validação do cordel

O texto do cordel deve ser feito em sextilha. No software existe um sistema validador desse tipo de texto (botão Concluir). Essa validação verifica se o trabalho contém título, xilogravura e texto em sextilha, caso não for preenchido algum desses requisitos surge uma mensagem de ajuda informando os pré requisitos necessários (figura 4). É preciso destacar que a validação da sextilha se dá apenas em número de versos, não havendo qualquer implementação que verifique a presença das rimas para esse formato de texto.

O usuário tem a opção de gerar um arquivo PDF com a sua produção, única forma de poder acessar posteriormente o cordel produzido. Contudo, dessa forma o aluno pode visualizar sua produção em diversos dispositivos e socializar com os membros da comunidade escolar (por impressão, por exemplo) ou mesmo fora da escola.

É preciso evidenciar que em todas as telas das atividades estão disponíveis, no canto superior direito, um botão de ajuda que apresenta informações sobre a navegação para realização da atividade. Bem como, estão disponíveis botões de navegação (menu, voltar e exemplos), que possibilitam ao usuário abandonar a atividade a qualquer momento que deseje e iniciar uma outra atividade. Todo o funcionamento do OA pode ser visto no vídeo disponível em https://youtu.be/j6sfdnHIm6U.

\section{Considerações finais}

A deficiência no letramento dos brasileiros é comprovado não somente nas pesquisas, como também no cotidiano escolar. Essa foi uma das motivações que levou este grupo a desenvolver o Encantando Cordel, com vistas a possibilitar que o professor trabalhe com seu aluno diversas habilidades em diferentes competência da Língua Portuguesa, do Raciocínio Lógico e das Artes, aproximando o aluno da vasta e enriquecedora cultura nordestina por meio da literatura de Cordel.

O processo de desenvolvimento no decorrer da disciplina oportunizou aos alunos que nunca vivenciaram a construção de um SEL a aplicar conhecimentos técnicos e pedagógicos prévios, adquiridos nesta disciplina e em outras disciplinas. Com isso, ampliou-se o leque de experiências adquiridas na academia que tem ainda caráter profissional, no escopo de atuação do profissional da Computação.

Por se tratar de um grande grupo dividido em outros três, cada um incubido de uma responsabilidade, ocorreu, inicialmente, uma dificuldade na sincronização das equipes, pois cada equipe dependia de alguma forma do produto gerado pela outra. Isso culminou em situações que exigiam habilidades de trabalho em equipe, resolução de problemas e gestão de tempo para o cumprimimento dos prazos estabelecidos. Por isso, o Encantando Cordel possui, ainda, funcionalidades que precisam ser melhoradas e acrescentadas, para ampliar e otimizar a experiência do usuário com o SEL.

Como trabalho futuro é prevista uma avaliação acerca da aplicação do software 
em sala de aula, analisando o uso por parte dos professores e alunos dos ensino fundamental, extraindo informações e feedback dos usuários. Com isso, espera-se que sejam identificadas demandas que elevem o potencial pedagógico do Encantando Cordel.

\section{Referências}

Almeida, M. E. B. (2008). “Tecnologias e conteúdos multimidiáticos na Educação Básica". 26 slides.

Brasil. Ministério da Educação. (2016). "Resultados da Avaliação de Leitura". Brasília: INEP, $14 \mathrm{p}$.

Brasil. (2017). "Base Nacional Comum Curricular". Disponível em: <http://basenacionalcomum.mec.gov.br/abase/\#fundamental/lingua-portuguesa>. Acesso em: 30 de Junho de 2019.

Oliveira, A. M. D. et al. (2017). "Levantamento e Catalogação de Objetos de Aprendizagem para Matemática para Atualização de um Repositório". In: Anais do Congresso sobre Tecnologias na Educação (Ctrl+E 2017). Mamanguape-PB, p.47-58.

Maia, D. L.; Pinheiro, J. L.; Arrais, G. de A. (2015). "Cultura Livre: fundamentos éticos para as TDIC na Educação". In: RIBEIRO, R. et al. (Orgs.). Ética, Sociabilidade e Educação. 1ed. Fortaleza: EdUECE, p.187-198.

Oliveira, A. M. D. et al. (2016). "Software Educativo Brincálculo". In: Congresso sobre Tecnologias na Educação (Ctrl+E 2016) - Universidade Federal do Rio Grande do Norte, 2018, Natal, p.640-645.

Oliveira, A. M. D. et al. (2018). "Software Educativo ContaKg". In: Congresso sobre Tecnologias na Educação (Ctrl+E 2018) Universidade Federal do Ceará, Fortaleza, p.590-596.

Oliveira, C. C.; Costa, J. W. da; Moreira, M. (2001). "Ambientes informatizados de aprendizagem: produção e avaliação de software educativo". 1ed. Campinas, SP: Papirus (Coleção Prática Pedagógica).

Papert, S. (2008). "A máquina das crianças: repensando a escola na era da informática". Tradução de Sandra Costa. Ed. revisada. Porto Alegre: Artmed.

Silveira. S. A. (2004). "Software livre: a luta pela liberdade do conhecimento". Editora Fundação Perseu Abramo, pp 9-23.

Valente, J. A. (1997). "Informática na educação: instrucionismo x construcionismo". Manuscrito não publicado, NIED: UNICAMP. 